\title{
Abortion is an Information Issue
}

\section{Author}

Hope Reilly, MLIS (2016, University of Maryland)

\begin{abstract}
In the years following the 1992 Supreme Court decision, Planned Parenthood v. Casey, abortion has been subjected to a wide range of legal restrictions, and the impact of these restrictions has not been adequately studied. While this process of increasingly restrictive regulation may be considered a public health issue, the natures of these laws also make them relevant to information studies. Biased counseling laws mandate that an abortion provider disseminate information specifically designed to discourage a woman from obtaining an abortion. This paper examines the impact of these laws on both the abortion patient and provider. Biased counseling information has a demonstrable effect on the health information access of abortion patients and on the intellectual freedom of abortion providers. However, there are also chilling effects on the intellectual freedom of the abortion patients themselves. This paper establishes abortion as an information issue and calls for future study into its effects on information access and intellectual freedom.
\end{abstract}

Keywords: abortion, information access, intellectual freedom, biased counseling laws, reproductive health

\section{Introduction}

bortion has been legal in all 50 states since 1973, but it is substantially more

1 difficult for women in some states to exercise their constitutionally protected right to the procedure. For example, while abortion is an extremely safe procedure$97.9 \%$ of abortions have no complications and only .23\% of abortions resulted in a major complication requiring hospital admission (Advancing New Studies in Reproductive Health, 2014) - 25 states regulate abortion providers beyond what is needed to ensure patient safety (Guttmacher Institute, n.d.). One type of legal restriction that has a broader impact is biased abortion counseling information. A biased counseling law is any law that mandates the disclosure of information designed to discourage a woman from terminating her pregnancy (Vandewalker, 2012, p. 3). Thirty-five states require counseling before an abortion, and 27 of them mandate the content of said counseling (Guttmacher Institute, 2015a). Several states require that doctors tell their patients information that is both scientifically inaccurate and contrary to standard medical practice. Five states (Alaska, Kansas, Mississippi, Oklahoma, and Texas) out of the seven that provide information about the links to breast cancer misrepresent the level of risk (Guttmacher Institute, 2015b). Nine states (Kansas, Louisiana, Michigan, Nebraska, North Carolina, South Dakota, Texas, Utah, and West Virginia) out of the 22 that include information on possible psychological responses stress that women feel negative emotional responses after an abortion (Guttmacher Institute, 2015b), implying that women run the risk of significant psychological harm. While this information appears

International Journal on Information, Diversity and Inclusion, Vol. 1, 2016 publish.lib.umd.edu/IJIDI/ 
neutral at first glance, it is actually deliberately designed to convince women that abortion is dangerous. However, even accurate information is not necessarily useful if it is not relevant to the individual or issue at hand.

Biased counseling information laws prevent women from meaningfully accessing information that would allow them to make fully autonomous decisions about their abortion care. Furthermore, the existence of these laws also helps create an environment where neither the doctor nor the patient can truly exercise their intellectual freedom. This paper will demonstrate that biased counseling laws and mandatory ultrasound laws have a significant negative impact on health information access, the intellectual freedom of abortion providers, and the intellectual freedom of patients. Additionally, this paper will also raise suggestions for significant further study into this topic because of its importance in the fields of health sciences and information studies. While access to appropriate reproductive health services for teenagers is important, this paper will only discuss this topic within the context of services for adults. Biased counseling information is objectionable because it is based on ideology that discounts the decision-making capacity of adult women. Children under the age of 18 are not held to the same standards as adults in other legal, decision-making capacities, so their ability to make autonomous decisions about their reproductive care is outside of the scope of this discussion.

\section{Information Access and the Right to Medical Information}

Accurate medical information is a human right. The Universal Declaration of Human Rights, which was passed by the United Nations shortly after the Second World War, states that all people have the "right to a standard of living adequate for the health and well-being of himself and of his family, including food, clothing, housing and medical care and necessary social services" (U.N. General Assembly, 1948). An individual needs information about their medical history, the nature of their illness or condition, and about their options for treatment in order to make informed decisions about their care. If people have the right to both medical care and the right to receive information without barriers, then they also have the right to accurate medical information. Abortion is - for now - a legal medical procedure protected by a 1973 Supreme Court decision based on constitutional rights. If everyone has a right to access accurate medical information, then abortion information is included within that right.

The prevalence of biased abortion counseling information is an information access issue because laws mandate the transmission of information that is false, irrelevant, harmful, or some combination of the three. The Merriam-Webster Dictionary defines access as the "freedom or ability to obtain or make use of something" (Access, n.d.). Mathiesen defines information access as when a person "has the freedom or opportunity to obtain, make use of, and benefit from...information" (Mathiesen, 2014, p. 607). True access to information is more complicated than having physical access to said information: in addition to physically obtaining the desired information, one must also have social and intellectual access to that information (Burnett, Jaeger, \& Thompson, 2008). An individual has intellectual access to a document if they can understand the information presented to them. Social access to information depends on the norms and values of a person's environment, and these social norms can impact or limit information access (Burnett et 
al., 2008). In sum, information that is accessible for one person is not necessarily accessible to others and one should be able to benefit from that information for it to be accessible. Accurate abortion information is not fully accessible for all women in the United States because it never makes it to them (which is a physical access issue) or conditions exist that prevent that information from being beneficial (which is an intellectual and/or a social access issue).

Biased counseling laws prevent women from having full access to accurate medical information because they restrict physical access to abortion information, which then compounds the existing lack of intellectual and social access to that information. Studies show that women from lower socioeconomic backgrounds and women who are black or Hispanic are less likely than white and middle-class women to seek out health information for reasons including inability to search for health information privately (Kim \& Zhang, 2015), distrust of medical officials, and reliance on family networks for information sharing (Richardson, Allen, Xiao, \& Vallone, 2012). If the government is deliberately providing misleading information to women, then it is violating their right to accurate medical information. For example, South Dakota and Utah require providers to tell their patients that they are at risk of contracting "post-abortion stress syndrome" when no such illness exists (Medoff, 2009, p. 634) and research has shown that women who receive abortions are at no higher risk of developing post-traumatic stress disorder than women who continue their pregnancies (Biggs, Rowland, \& Foster, 2015). Overall, the scientific consensus is that abortion in and of itself does not cause psychological problems (Vandewalker, 2012). If these laws lead to women making decisions to continue pregnancies based solely on false information, then they reduce women's autonomy (Vandewalker, 2012). These women then have limited intellectual access to accurate abortion information because they are often unaware that they are missing that information. Women who live in communities with cultural norms prohibiting open discussion of both abortion and general women's health issues are less likely to be able to access accurate abortion information.

Abortion providers are well aware of the restrictions placed on them, but manage to provide accurate medical information to their clients without violating the law. A 2012 study found that front-line staff members overwhelmingly gave first-time callers accurate information (Dodge, Haider, \& Hacker, 2012). There were no differences between providers in the most and least restrictive states (Dodge et al., 2012). The Advancing New Standards in Reproductive Health (ANSIRH) group at the University of California, San Francisco, released a set of clinical guidelines on ultrasound viewing in abortion care in 2014. These guidelines are centered around making decisions based on the best interests of the patient (Perrucci, 2014). They recommend that providers be honest about when and why state mandates conflict with best practices, but without being inflammatory or communicating resentment and hostility. Abortion providers regularly adapt statemandated information to minimize the perceived negative effects (Mercier, Buchbinder, Bryant, \& Britton, 2015). Abortion providers comply with these mandates while also being honest about why they exist and their perceived impacts on patient care - their attempts at mitigating the impact of biased counseling laws have created alternate avenues for access to abortion information. 
However, this increased level of access actually works to obscure the fact that there is an access problem in the first place - the few studies done on this topic have shown that patients are generally unaware of abortion laws. A 2010 study where researchers interviewed patients at high-volume abortion clinics in states with biased counseling laws found that these women were generally unaware that those laws existed and were unable to distinguish the biased information mandated by the state from the information that the clinic provided in its own counseling services (Cockrill \& Weitz, 2010). This suggests that there are information literacy issues related to both reproductive health and policy information. Women generally supported the idea of abortion counseling, but only if it was not designed to discourage or trick them into not continuing with the procedure (Cockrill \& Weitz, 2010). Women agree that informed consent is important, but their concern is misplaced because informed consent is an essential component of medical practice and exists in abortion care regardless of state mandate. This suggests that many women mischaracterize or misinterpret the nature of biased counseling information because of a fundamental lack of awareness about this information environment.

Women who obtain abortions in states without biased counseling information laws are not subject to the same barriers to access as women living in states that do have themfor example, a woman living in Texas with no regular Internet access and little sexual education essentially depends on the staff in the clinic she visits to give her accurate information. There should be further research examining how abortion providers comply with biased counseling laws, because even if most providers try to help their patients make informed decisions in spite of the law, the state is still mandating that they disseminate information that is demonstrably false. How does this affect the intellectual freedom of abortion seekers?

\section{Intellectual Freedom of Patients}

\section{Reactions to Counseling}

Biased counseling laws attempt to use informed consent procedures to indoctrinate women and interfere with their decision-making. This practice violates the principles of intellectual freedom because it de-legitimizes actions and thought processes other than the ones sanctioned by the state.

While biased counseling laws are centered around conveying the moral value of the fetus to the woman, the little research that has been conducted on this topic has found that women's actual counseling needs are much more complex. A 2011 study found that information contained in biased abortion counseling was not always relevant to each individual woman (Moore, Frohwirth, \& Blades, 2011). The few women who sought options counseling, where a pregnant person speaks to a health professional or counselor for the purpose of determining the outcome of her pregnancy, wanted factual information instead of an emotional dialogue with the counselor (Moore et al., 2011). A 2012 study found that women who report negative emotional responses after an abortion usually attribute those feelings to relationship loss (be it the end of a romantic relationship or the loss of a parent-child relationship) or societal disapproval of abortion rather than to fetal loss (Kimport, 2012). Biased counseling laws attempt to create an environment where women make decisions purely based on two pre-determined options for emotion- 
accepting or rejecting the moral status of the fetus - but women's emotions are clearly more complex than that. A woman can recognize that her fetus has moral value to her and still have many reasons to terminate her pregnancy.

Furthermore, the women who refused options counseling also had complex and varied reasons for declining them. First of all, most women in the aforementioned study reported that they did not want options counseling because they had made their decision to terminate before calling the clinic (Moore et al., 2011). However, women who were sure of their decision felt that they still had counseling needs outside of deciding whether or not they wanted to be mothers: these needs included reassurance that the procedure was legal, dealing with the difficulty of their decision, and internalized and/or perceived stigma (Moore et al., 2011). These women have information needs that clinic counselors are trying (and usually succeeding) to meet, but many of them arguably would not exist in an environment more hospitable to reproductive rights. This shows that there is a significant difference between the attitudes that influence policy and the reality of women's experiences. How do healthcare providers balance the needs of their patients with their legal obligations?

\section{Informed Consent and the Intellectual Freedom of Providers}

The American Library Association defines intellectual freedom as "the right of every individual to both seek and receive information from all points of view without restriction" (American Library Association, n.d., para. 1). Biased abortion counseling laws violate the intellectual freedom of physicians because they interfere with best practices surrounding obtaining informed consent and prevent physicians from being able to make silent decisions, which are fundamental to abortion care.

Informed consent is "the process by which the treating health care provider discloses appropriate information to a competent patient so that the patient may make a voluntary choice to accept or refuse treatment" (De Bord, 2014, para. 2). There is no medical reason to have an informed consent procedure unique to abortion. Women understand that undergoing an abortion means ending their pregnancy and not undergoing an abortion means continuing with the pregnancy. Instead of providing information to facilitate autonomous choice, biased counseling laws use informed consent as an obstacle to abortion access (Vandewalker, 2012). While providers in North Carolina (a state that passed a restrictive Women's Right to Know law in 2011 that, among other restrictions including a 24-hour waiting period, mandated that physicians show and describe a woman's ultrasound picture to her) continued to practice their existing informed consent procedures alongside the state-mandated ones, they indicated that "complying with the law created a substantial institutional burden" (Mercier et al., 2015, p. 509). Instead of creating guidelines that give women useful and relevant information to help them make decisions, these laws instead drive up costs and create stress for providers.

Biased counseling information laws prevent physicians from being able to make certain silent decisions in the context of abortion care. Silent decisions are "conscious choices that clinically affect the patient but are not disclosed to the patient" (Whitney \& McCullough, 2007, p. 33). This term is used in medical literature to describe when a doctor withholds information about a potential procedure to a patient because the potential harm in 
explaining outweighs the benefit and the physician does not want to add to patient anxiety. Doctors are obligated to tell the truth when patients ask about the remote possibilities, but they should not mention every remote possibility solely for the sake of mentioning them. Physicians make silent decisions because providing a patient with too much information about a topic can be as harmful as providing them with too little (Vandewalker, 2012). Physicians should consider the "nature, magnitude, probability, and imminence" of a risk before deciding to disclose it (Vandewalker, 2012, p. 50), so there is no reason to include the exaggerated risk statements in state-mandated, biased counseling information. These laws force doctors to mention risks without explaining the likelihood of them occurring, and they focus on the negative effects of abortion over its positive effects or the negative effects of childbirth (Vandewalker, 2012). This forces doctors to promote the opinions of the state that counteract their professional opinion and prevents them from fully practicing medicine. Why are they being forced to do this, and what does it mean?

\section{Sexist Attitudes and Policy}

Policymakers cannot outlaw abortion, so the prevailing strategy of abortion opponents is to add burdensome regulations until it is almost impossible for women to obtain the procedure. While some legislatures mask their efforts by claiming that they are working to improve women's health, some politicians openly admit their motives. When signing the state's Targeted Regulation of Abortion Providers bill in 2012, Mississippi governor Phil Bryant stated that "Today you see the first step in a movement to do what we campaigned on....to try to end abortion in Mississippi" (Gold \& Nash, 2013, p. 10). Antiabortion lobby group Americans United for Life helped enact 38 state laws between 2013 and 2015 with the explicit goal to limit abortion access at the state level - in a 2015 interview, their president likened their quiet legal strategy to a game of chess (Khazan, 2015). This practice has serious implications for intellectual freedom in that the government is promoting one negative view of abortion over neutral, positive, and/or nuanced views of the procedure.

Between the 1973 Roe decision and the early 1990s, state laws requiring doctors to disseminate information designed to discourage women from obtaining abortions (i.e., biased counseling laws) were overturned because they were rightfully seen as interfering with a woman's freedom of choice (Dresser, 2008). In 1992, the Supreme Court reviewed a challenge to the 1982 Pennsylvania Abortion Control Act and upheld a woman's legal right to abortion. However, this case established a precedent that some limits on abortion access were constitutional if they did not pose an "undue burden" on women's healthPennsylvania's spousal notification requirement was seen as an undue burden, but a 24hour waiting period was not. The court found that the state had an interest in "promoting human life," was permitted to express a preference for childbirth, and that informed consent practices that advanced a pregnant woman's "psychological well-being" were legitimate state interests. The Casey decision effectively legalized biased counseling laws because the state's interest in discouraging abortion was considered more important than these laws' effects on women's decision-making. This was based on the erroneous belief that women have a psychological vulnerability that prevents them from fully understanding the nature and consequences of abortion (Dresser, 2008). 
Supporters of biased counseling laws believe that women do not understand that abortion is wrong and that they will not have them if that message is conveyed to them. Oklahoma state senator Todd Lamb acknowledged that his state's ultrasound law existed to reduce abortions because he believed that an ultrasound conveys the moral status of a fetus to the woman (Vandewalker, 2012). Not only does this law force a woman to undergo an invasive procedure regardless of medical necessity, but it is also designed to change how she thinks - this is an unmistakable attack on intellectual freedom.

\section{Ultrasound}

If biased counseling laws exist to change how women think, then mandated ultrasound laws are the most extreme manifestation of this practice. Legislators enact laws to mandate ultrasound viewing in abortion care contexts because they believe that it will facilitate fetal-maternal bonding and ultimately dissuade women from continuing with the procedure. The few studies conducted on this topic show that this practice is ineffective.

First of all, the research on the effects of viewing ultrasound images was conducted only in wanted pregnancies (Kimport, Preskill, Cockrill, \& Weitz, 2012), so there is no evidence that it will produce the same effects in an unwanted pregnancy. Furthermore, most women who view their ultrasound in an abortion care context chose to continue with the procedure. A 2013 study researching women who opted to view their ultrasound during the process of seeking abortion care for an unwanted pregnancy found that $98.4 \%$ of patients proceeded to termination after viewing the ultrasound and that the only patients who opted to continue the pregnancy were already unsure of their decision before viewing the ultrasound (Kimport, Upadhyay, Foster, Gatter, \& Weitz, 2013). Additionally, women who are less sure of their decision either way are more likely to opt to view the ultrasound (Kimport et al., 2013). The vast majority of the women who viewed their ultrasounds had already made the decision to terminate and chose to see them because of cultural norms or to help them make peace with a decision they had already made (Kimport et al., 2013). This further illustrates the complexity of women's feelings, attitudes, and experiences about their abortions. While some respondents felt that viewing the ultrasound was a "natural" part of the pregnancy process, none of the respondents supported mandatory viewing of the ultrasound (Kimport et al., 2012). Women opposed mandated ultrasounds because they found the information to be irrelevant, harmful, and/or biased.

This major difference between the policy and reality raises several information questions. Women are presented with information designed to make them not want to get an abortion. This only seems to sway women who are already undecided, but are those women making fully autonomous decisions? Indecisive people deserve the same information as decisive ones. Additionally, these practices are attempts to influence women's thinking that are mostly - but not entirely - ineffective. However, attacks on intellectual freedom are still attacks, even if they are unsuccessful - these women are still forced to endure informed consent procedures that are predicated on the belief that they do not have the decision-making capacity of an adult. What kind of impact does that have? 
One example of this hostility is the use of the ultrasound to intimidate women. Out of the 25 states that require that a woman undergo a trans-vaginal ultrasound prior to receiving an abortion, regardless of medical necessity, Louisiana, Texas, and Wisconsin also force those women to view and listen to a description of the image with few mitigating exceptions (Guttmacher Institute, 2015b). Forced medication is considered a form of battery (Louisiana State University, 2009), so forced ultrasounds can be considered forms of physical violence. Some Texas clinics, recognizing the impact on their patients, offer the woman a pair of headphones to wear so that she is not forced to listen to something she may not want to hear (Filipovic, 2014).

There is evidence that mandated viewing of the ultrasound hurts women. In one study, one woman reported that viewing her ultrasound did not change her mind but exacted an emotional toll (Kimport et al., 2012). In a separate study examining the effects of North Carolina's abortion restrictions on providers, a patient who terminated a wanted pregnancy because of fetal abnormalities began to cry and stated "I can't do that. I can't believe I have to go through this again" after being read the state-mandated script (Mercier et al., 2015, p. 510). Providers are aware of these effects and reported that they felt that all women, especially rape victims at risk of being further traumatized, should not be forced to participate in conversations that are "emotionally damaging" (Moore et al., 2011 , p. 440). Forcing a woman to view and listen to a description of her fetus serves no medical purpose. Why ask women to do something that serves no purpose?

\section{Intimidation and Violence}

While biased counseling information is demonstrably false and ineffective in conveying a state-sanctioned moral doctrine to abortion patients to convince them to continue with their pregnancies, it succeeds in contributing to an environment that makes women afraid to seek reproductive health services.

There is an existing culture of intimidation surrounding women's reproductive health, and abortion providers receive the worst of it. Abortion providers are targets of violence - many abortion clinics have extra security, including safe rooms, bulletproof windows, and cameras (Healy \& Eckholm, 2015). Eleven people, including four doctors, have been killed at abortion clinics since 1993 (Padilla, 2015). There are countless stories of abortion clinics being firebombed, doctors being followed home, clinic escorts being stalked, clinic employees being harassed outside of work, and both providers and patients being killed. One example of this violence was the 2015 mass shooting at an abortion clinic in Colorado where three people were murdered by a domestic terrorist motivated by anti-abortion rhetoric (Turkewitz, 2015). Both abortion clinics and Planned Parenthood clinics that do not perform abortions frequently experience protester harassment directed at both providers and patients. Politicians are also open about both their feelings about women's bodily integrity and their lack of knowledge about human reproduction. For example, a Virginia state lawmaker referred to pregnant women as "[children's] hosts" (Kim, 2014), which is dehumanizing because it centers the conversation on the fetus instead of on the woman seeking the abortion. Former Missouri Representative Todd Akin stated that rape victims should not be permitted to get abortions because "legitimate rape" does not result in pregnancy (Moore, 2012). This is 
particularly egregious because it shows a fundamental lack of understanding about human anatomy - or at least that this man has made a deliberate choice to present himself as someone who does not understand human anatomy. Clearly this is an environment that is already hostile to reproductive choice. There should be further research on the use of false information as an intimidation tactic. What is the impact of biased counseling information on women who know that the information is false?

\section{Larger Impact and Further Study}

A woman's autonomy is threatened by false and misleading information, but the greater danger to her decision-making is the societal perception that she lacks autonomy. All of the issues raised in this paper deserve further consideration, both in and outside of the field of information studies, because of the impact abortion restrictions have on women's health and intellectual freedom.

Furthermore, government officials' attitudes toward abortion have also infringed on the intellectual freedom of people who are not seeking abortion procedures. In October of 2015, a Missouri state lawmaker sent a letter to the chancellor of the University of Missouri asking him to bar a doctoral student from writing her dissertation on the impact of Missouri's 72-hour waiting period (Adler, 2015). Senator Kurt Schaefer claimed that this study would violate the Missouri law that forbids tax dollars from "encouraging" a woman to have an abortion unless it saves her life, which suggests that he believed that the dissertation would inevitably cast the waiting period law in a negative light. But what if this student's findings ended up discouraging women from having abortions? This censorship attempt is a clear example of the intellectual freedom issues surrounding abortion.

There should also be further study into the impact of forced ultrasounds on women seeking abortions. First of all, women are forced to transmit information about themselves to their doctors through mandated ultrasounds. What are the effects of an invasive and often medically unnecessary procedure on women who are already dealing with making a controversial and intensely personal decision? This suggests additional privacy-related issues. For example, mandated ultrasounds lead to the creation of ultrasound images. Who owns the intellectual property rights to those images? Are they recorded and, if so, are they ever permanently destroyed? What is the impact of mandatory ultrasound laws on the record-keeping practices of abortion clinics?

Abortion is an information issue because information is used as a means of preventing or dissuading women from undergoing abortions and a means of assault on the legal standing of abortion as a medical procedure. There is so much potential for future study into the intersection of abortion and information. How does biased counseling information affect health information literacy? This issue is also important from an information standpoint because it deals with information disseminated by the government and government interference with medical information in a doctor-patient setting. There are parallels between biased counseling laws and legislation limiting gun research. The CDC has been banned from studying gun violence since 1996 and several other government agencies have voluntarily ended their research into gun violence for fear of losing grant money (Frankel, 2015). In the state of Florida, it is illegal for doctors to ask 
patients if they live in a home with a firearm (Medical privacy concerning firearms; prohibitions; penalties; exceptions, 2011), and similar bills have been proposed in several other states (Rathmore, 2014). The United States is an extreme outlier for gun violence in the developed world (Quealy \& Sanger-Katz, 2016), and children who live in a house with a firearm are significantly more likely to be injured or killed by gun violence (Dahlberg, Ikeda, \& Kresnow, 2004). Gun violence is a widespread and well-documented problem, so why is the federal government not treating it as a public health issue? There should be further study into how access to information about guns is affected by these gag laws and whether or not this cascades into effects on information literacy and intellectual freedom. However, at first glance, there are striking similarities to the ideology-based attacks on abortion information access and patient and provider intellectual freedom. Biased counseling information is worthy of study outside of the contexts of political science and reproductive justice.

\section{Conclusion}

The status of legal abortion is so precarious that the outlook for reproductive rights has changed rapidly in the time in which this piece was prepared for publication. In January 2016, North Carolina implemented a law requiring abortion providers to submit ultrasound documentation verifying gestational age for all abortions performed after 16 weeks of pregnancy (Fausset, 2016). In addition to sending the ultrasound image to the state Department of Health, providers must also include measurements of the fetus' femurs and the diameters of their gestational sacs - information that has no medical purpose (Bever, 2016). This law was almost certainly designed to create additional barriers to obtaining abortions in North Carolina and raises questions about the state bureaucracy's ability to guarantee the privacy of these patients. In February 2016, Supreme Court Justice Antonin Scalia died unexpectedly and Senate Republicans refused to hold hearings to consider President Obama's appointment, Merrick Garland. In June 2016, the Supreme Court handed down a 5-3 decision in Whole Woman's Health v. Hellerstadt that overturned several targeted abortion regulations that served no medical purpose. This decision found that Texas' restrictions requiring physicians to have admitting privileges at nearby hospitals and clinics to meet the unnecessary standards of ambulatory surgical centers were unconstitutional because they posed an undue burden on women (Liptak, 2016). This precedent could also potentially lead to later decisions that would overturn biased counseling laws. However, both this new precedent and meaningful abortion access could be overturned altogether with the 2016 election of Donald Trump. While Trump has made conflicting statements about his views on abortion - he supported the legal right to the procedure until 2011 but said during the 2016 campaign that women who have abortions should be punished - his running mate Mike Pence is openly opposed to abortion rights (Shepherd \& Rappaport, 2016). As governor of Indiana, Pence signed a law requiring facilities that provide abortion to pay for the cremation or burial of fetal remains and stated during the campaign that he would work to have "Roe vs. Wade consigned to the ash heap of history where it belongs" (Mehta, 2016, para. 2). As of November 2016, Merrick Garland has not been confirmed to the Supreme Court. Unless Garland gets confirmed before Trump takes office, Scalia's successor will be a Trump (or Pence) appointee - or the court will continue to operate 
under capacity. If the Supreme Court agrees to hear a case challenging Roe v. Wade, then there is a chance that women in the United States could lose their right to a legal abortion.

Information professionals should care about abortion from both a philosophical standpoint and from a practical one. Academic libraries have participated and do participate in health information outreach on their campuses (Duhon \& Jameson, 2013) ranging from mitigating the impact of cold and flu season to spreading awareness about preventing sexual assault. How would information about abortion fit into this existing framework? Public libraries are already sources of medical information for a significant portion of the American public, so there is a chance that public libraries could also be the front-line source for reproductive health information in the event that abortion services become substantially more difficult to obtain. If the procedure is outlawed in certain states or banned entirely, then library professionals will have to adapt - helping women get abortion-related information may replace bomb making and assisted suicide as the perennial ethics case study in library school.

This paper has demonstrated that abortion restrictions have had a significant impact on intellectual freedom. Biased counseling laws and other abortion restrictions contribute to an environment where people cannot speak openly and honestly about abortion. Furthermore, these laws are predicated on the belief that women cannot and should not make autonomous decisions. This sets a dangerous precedent that could have a wider impact on both the information profession and on women's rights. There should be a larger discussion in librarianship about its history as a woman's profession - in 2015, 83\% of librarians were women (Department of Professional Employees: AFL-CIO, 2016) and abortion should be part of that discussion. Information professionals are supposed to provide equal and open access to useful information and help create environments where lay people can adequately search for and critically evaluate quality information resources. Our field should be concerned with orchestrated attempts to use false information to mislead the public, especially when it concerns half of the population and the majority of our profession. Abortion is an information issue and no woman - or information professional— should be afraid to talk about it. 


\section{References}

Access. (n.d.). In Merriam-Webster's online dictionary. Retrieved from http://www.merriamwebster.com/dictionary/access

Adler, J. (2015, November 12). Missouri state senator seeks to block University of Missouri student's dissertation on abortion regulations. Washington Post, Retrieved from https://www.washingtonpost.com/news/volokhconspiracy/wp/2015/11/12/missouri-state-senator-seeks-to-block-university-ofmissouri-students-dissertation-on-abortion-regulations/

Advancing New Studies in Reproductive Health (ANSIRH). (2014 December). Safety of Abortion in the United States. Issue Brief \#6. Retrieved from http://www.ansirh.org/sites/default/files/publications/files/safetybrief12-14.pdf

American Library Association. (n.d.). Intellectual Freedom and Censorship Q \& A. Retrieved November 15, 2015, from http://www.ala.org/advocacy/intfreedom/censorshipfirstamendmentissues/ifcen sorshipqanda

Bever, L. (2016, January 16). Why ultrasounds are intensifying North Carolina's abortion fight. Washington Post, Retrieved from https://www.washingtonpost.com/news/post-nation/wp/2016/01/16/whyultrasounds-are-intensifying-north-carolinas-abortion-fight/

Biggs, M. A., Rowland, B., \& Foster, D. G. (2015). Does abortion increase women's risk for posttraumatic stress disorder? Contraception, 92(4), 359.

Burnett, G., Jaeger, P. T., \& Thompson, K. M. (2008). Normative behavior and information: The social aspects of information access. Library E Information Science Research, 30(1), 56-66.

Cockrill, K., \& Weitz, T. (2010). Abortion patients' perception of abortion regulation. Women's Health Issues, 20(1), 12-19.

Dahlberg, L., Ikeda, R., \& Kresnow, M. (2004). Guns in the home and risk of a violent death in the home: Findings from a national study. American Fournal of Epidemiology, 160(10), 929-936.

De Bord, J. (2014, March 7). Informed Consent. Seattle: University of Washington School of Medicine. Retrieved from https://depts.washington.edu/bioethx/topics/consent.html

Department of Professional Employees: AFL-CIO. (2016). Library Workers: Facts and Figures. Retrieved from http://dpeaflcio.org/programs-publications/issue-factsheets/library-workers-facts-figures/

Dodge, L., Haider, S., \& Hacker, M. (2012). Knowledge of state-level abortion laws and policies among front-line staff at facilities providing abortion services. Women's Health Issues 22(5), 415-420.

Dresser, R. (2008). From double standard to double bind: Informed choice in abortion. George Washington University Law Review, 76(6) 1599-1622. 
Duhon, L., \& Jameson, J. (2013). Health information outreach: A survey of U.S. academic libraries, highlighting a Midwestern university's experience. Health Information E Libraries Fournal, 30(2), 121-137.

Fausset, R. (2016, January 10). Law on ultrasounds reignites abortion battle in North Carolina. The New York Times. Retrieved from http://www.nytimes.com/2016/01/11/us/law-on-ultrasounds-reignitesabortion-battle-in-north-carolina.html

Filipovic, J. (2014, July 8). How Texas created a culture of shame. Cosmopolitan. Retrieved from http://www.cosmopolitan.com/politics/news/a28327/abortion-stigmatexas/

Frankel, T. (2015). Why the CDC still isn't researching gun violence, despite the ban being lifted two years ago. The Washington Post. Retrieved from https://www.washingtonpost.com/news/storyline/wp/2015/01/14/why-thecdc-still-isnt-researching-gun-violence-despite-the-ban-being-lifted-two-years-ago/

Gold, R. B., \& Nash, E. (2013). TRAP laws gain political traction while abortion clinicsand the women they serve - pay the price. Guttmacher Policy Review, 16(2), Retrieved from https://www.guttmacher.org/about/gpr/2013/06/trap-lawsgain-political-traction-while-abortion-clinics-and-women-they-serve-pay

Guttmacher Institute. (2015a, September 1). State policies in brief: An overview of abortion laws. Retrieved September 23, 2015 from http://www.guttmacher.org/statecenter/spibs/spib_OAL.pdf

Guttmacher Institute. (2015b, September 1). State policies in brief: Counseling and waiting periods for abortion. Retrieved September 23, 2015 from http://www.guttmacher.org/statecenter/spibs/spib_MWPA.pdf

Guttmacher Institute. (n.d.). State policies in brief: Targeted regulation of abortion providers. Retrieved October 30, 2016 from https://www.guttmacher.org/statepolicy/explore/targeted-regulation-abortion-providers

Healy, J., \& Eckholm, E. (2015, November 28). Siege highlights security used in abortion clinics. The New Tork Times. Retrieved from http://www.nytimes.com/2015/11/29/us/siege-highlights-security-used-inabortion-clinics.html?_r=0

Khazan, O. (2015, July 16). Planning the end of abortion. The Atlantic. Retrieved from http://www.theatlantic.com/politics/archive/2015/07/what-pro-life-activistsreally-want/398297/

Kim, C. (2014, February 26). Virginia Republican labels pregnant women as "hosts." $M S \mathcal{N B C}$, Retrieved from http://www.msnbc.com/the-last-word/state-sen-callspregnant-women-hosts

Kim, H., \& Zhang, Y. (2015) Health information seeking of low socioeconomic status Hispanic adults using smartphones. Aslib fournal of Information Management, 67(5), $542-561$ 
Kimport, K. (2012). (Mis)Understanding abortion regret. Symbolic Interaction, 35(2), 105122.

Kimport, K., Preskill, F., Cockrill, K., \& Weitz, T. (2012). Women's perspectives on ultrasound viewing in the abortion care context. Women's Health Issues, 22(6), 513517.

Kimport, K., Upadhyay, U., Foster, D., Gatter, M., \& Weitz, T. (2013). Patient viewing of the ultrasound image prior to abortion. Contraception, 88(5), 666-670.

Liptak, A. (2016, June 27). Supreme Court strikes down Texas abortion restrictions. The New Tork Times, Retrieved from http://www.nytimes.com/2016/06/28/us/supreme-court-texas-abortion.html

Louisiana State University. (2009, April 19). Battery-No Consent. Retrieved from http://biotech.law.lsu.edu/map/BatteryNoConsent.html

Mathiesen, K. (2014). Facets of access: A conceptual and standard threats analysis. iConference 2014 Proceedings, p. 605-611, Retrieved from http://hdl.handle.net/2142/47410

Medical privacy concerning firearms; prohibitions; penalties; exceptions. Florida Statute $\S$ 790.338 (2011).

Medoff, M. (2009). Biased abortion counseling laws and abortion demand. The Social Science Fournal, 46, 632-643.

Mehta, S. (July 28, 2016). Roe vs. Wade will be overturned if Donald Trump wins, Mike Pence says. The Los Angeles Times. Retrieved from http://www.latimes.com/nation/politics/trailguide/la-na-democraticconvention-2016-live-pence-says-roe-v-wade-will-be-1469737388-htmlstory.html

Mercier, R., Buchbinder, M., Bryant, A., \& Britton, L. (2015). The experiences and adaptations of abortion providers practicing under a new TRAP law: A qualitative study. Contraception (91), 507-512.

Moore, A., Frohwirth, L., \& Blades, N. (2011). What women want from abortion counseling in the United States: A qualitative study of abortion patients in 2008. Social Work in Health Care, 50(6), 424-442.

Moore, L. (2012, August 20). Rep. Todd Akin: The statement and the reaction. The New Tork Times, Retrieved from http://www.nytimes.com/2012/08/21/us/politics/rep-todd-akin-legitimaterape-statement-and-reaction.html

Padilla, S. (2015, November 29). Abortion violence's deadly toll spans clinics, kitchen, and church. Los Angeles Times. Retrieved from http://www.latimes.com/nation/la-naabortion-violence-20151129-htmlstory.html

Perrucci, A. (2014, September). Clinical guidelines on ultrasound viewing. Oakland, CA: ANSIRH. Retrieved from https://www.ansirh.org/sites/default/files/publications/files/ultrasound_guideli nes9-14.pdf 
Quealy, K., \& Sanger-Katz, M. (2016, June 13). Compare these gun death rates: The U.S. is in a different world. The New York Times. Retrieved from http://www.nytimes.com/2016/06/14/upshot/compare-these-gun-death-ratesthe-us-is-in-a-different-world.html?_r=0

Rathmore, M. (2014). Physician "gag laws" and gun safety. American Medical Association Fournal of Ethics, 16(4). 284-288.

Richardson, A., Allen, J. A., Xiao, H., \& Vallone, D. (2012). Effects of race/ethnicity and socioeconomic status on health information-seeking, confidence, and trust. Fournal of Health Care for the Poor and Underserved, 23(4), 1477-1493.

Shepherd, K., \& Rappaport, A. (2016, July 15). How Mike Pence and Donald Trump compare on the issues. The New York Times. Retrieved from http://www.nytimes.com/2016/07/16/us/politics/mike-pence-issues.html

Turkewitz, J. (2015, November 28). In Colorado, bustling with shoppers, then gripped by chaos. The New York Times, Retrieved from http://www.nytimes.com/2015/11/29/us/colorado-springs-plannedparenthood-shooting.html

U.N. General Assembly. (1948). Universal Declaration of Human Rights. Resolution 217 A (III). Retrieved from http://www.refworld.org/docid/3ae6b3712c.html

Vandewalker, I. (2012). Abortion and informed consent: How biased counseling laws mandate violations of medical ethics. Michigan fournal of Gender and Law, 19(1) 170 .

Whitney, S., \& McCullough, L. (2007). Physicians' silent decisions: Because patient autonomy does not always come first. The American Fournal of Bioethics, 7(7), 33-38. 